\title{
Quantitation of vitronectin in serum: Evaluation of its usefulness in routine clinical practice
}

\author{
N A M Boyd, A R Bradwell, R A Thompson
}

\begin{abstract}
Aims-To make a preliminary assessment of the clinical relevance of serum vitronectin concentrations in various disease groups, using a recently available commercial radial immunodiffusion kit. Methods-Serum vitronectin concentrations were measured in 80 control subjects and 144 patients with various diseases. The following characteristics were used to evaluate the test procedures: linearity of method, inter- and intrabatch precision, effect of storage, temperature and in vitro activation of the classical and alternative complement pathways on vitronectin concentrations. Results-Significantly reduced serum vitronectin concentrations were found in patients with liver disease, renal disease, and systemic lupus erythematosus (SLE) (normal C3 and C4 concentrations, when compared with normal subjects. This particular method was suitable for measuring vitronectin concentrations in serum samples provided they were stored at $-20^{\circ} \mathrm{C}$.

Conclusions-The clinical value of measuring serum vitronectin seems to be limited, but a larger study may be justified to ascertain the clinical importance of reduced serum vitronectin concentrations in liver diseases, and the possible role of vitronectin in other disease processes.
\end{abstract}

(F Clin Pathol 1993;46:1042-1045)

Vitronectin, also known as serum spreading factor, ${ }^{1}$ S-protein, ${ }^{2}$ and epibolin, ${ }^{3}$ is a multifunctional glycoprotein present in blood, urine, amniotic fluid ${ }^{4}$ and the extracellular matrix of tissue. ${ }^{5}$ It has a role in the regulation of both the complement ${ }^{6}$ and coagulation systems. ${ }^{78}$ Vitronectin binds membrane bound $\mathrm{C} 5 \mathrm{~b}-9^{9}$ and non-membrane bound C5b-9 ${ }^{10}$ and it is known to inhibit cell lysis in vitro. ${ }^{11}$ It also binds to heparin and neutralises the inactivation of thrombin by antithrombin III. ${ }^{12}$ Vitronectin has growth promoting activity, ${ }^{13}$ has recently been described as an opsonin, ${ }^{14}$ and is a cell adhesion molecule. ${ }^{15}$ The vitronectin receptor belongs to the beta ${ }_{3}$ integrin family which recognise the peptide sequence Arg-Gly-Asp (RSD) on cells. ${ }^{16}$ Vitronectin is a precursor of the serum peptide somatomedin B. ${ }^{17} 18$
The main organ of synthesis of vitronectin is the liver, ${ }^{19}$ but it is also produced by platelets, ${ }^{20}$ monocytes, macrophages, ${ }^{21}$ and megakaryocytes. ${ }^{22}$ It exists as two polypeptides of molecular weight 75000 kilodaltons (one chain form) and 65000 kilodaltons (two chain form) in plasma and serum. The 75000 kilodalton precursor yields the 65000 peptide by proteolytic cleavage at the $\mathrm{COOH}$ terminal. ${ }^{23}$ Individuals vary in the ratios of the one and two chain forms. ${ }^{24}$ Previous analysis of normal subjects and patients with thrombotic disorders showed three patterns: mostly two chain; equal amounts of both forms; and mostly one chain. Patterns are an inherited trait and are present in the Caucasian population in the ratios predicted by the Hardy Weinberg equilibrium of two alleles. ${ }^{25}$ The gene frequency for the trait varies in different populations. Caucasians have a lower frequency for the one chain form than Chinese ${ }^{26}$ and Japanese. ${ }^{27}$

Serum vitronectin concentrations do not differ significantly from plasma concentrations. ${ }^{28} \mathrm{~A}$ wide range of plasma concentrations for vitronectin have been reported between $0.14 \mathrm{mg} / 1^{11}$ and $0.6 \mathrm{mg} / 1 .^{29}$ The mean concentration measured in plasma in healthy subjects has been reported as 0.5 $\mathrm{mg} / 1 .{ }^{30}$ There is no significant difference between adult concentrations of plasma vitronectin in men and women and there is no significant change in the vitronectin concentration with age. ${ }^{4}$ The blood concentration measured in healthy newborns, however, is $67 \%$ of the adult level. ${ }^{31}$

Vitronectin plasma concentrations have been measured by rocket immunoelectrophoresis in patients with chronic liver disease; significantly decreased concentrations were found in patients with liver cirrhosis and these changes correlated closely with changes in serum cholinesterase, factor X, and C3. ${ }^{19} \mathrm{It}$ has been suggested recently that plasma concentrations of vitronectin may be useful as a parameter of hepatic synthetic function and as a marker of the severity of cirrhosis. ${ }^{32}$ Substantially reduced plasma vitronectin concentrations, measured by ELISA, have been reported in patients with disseminated intravascular coagulation, especially if liver failure is also present. Normal vitronectin concentrations have been detected in patients with acute leukaemia and metastatic cancer. ${ }^{25}$ There is as yet no clear understanding of the importance of these variations in the concentrations of vitronectin in different diseases. 


\section{Methods}

In evaluating the kit the following features were examined: linearity of method; interand intrabatch precision; sample type; effect of storage; effect of temperature; effect of in vitro activation of the classical and alternative complement pathway.

Two control samples and the calibrator provided with the kit were tested neat and at 1 in 2,1 in 4,1 in 8,1 in 16 dilutions in physiological saline. The neat sample was regarded as the true value.

For intrabatch analysis, one control serum sample was assayed neat and at a 1 in 2 dilution five times using the same kit. For interbatch analysis, one control serum sample was assayed on ten separate occasions. The coefficient of variation (CV) was calculated for each.

Serum and plasma (EDTA) samples on eight control subjects (four female and four male) were tested.

Two control serum samples were aliquoted and stored at $37^{\circ} \mathrm{C}, 4^{\circ} \mathrm{C}$, room temperature, $-20^{\circ} \mathrm{C}$ and $-70^{\circ} \mathrm{C}$ for five days before testing.

Two control samples were heated to $56^{\circ} \mathrm{C}$ before testing.

For classical complement pathway activation, $0.5 \mathrm{ml}$ aggregated IgG was added to an equal volume of one control serum sample and incubated at $37^{\circ} \mathrm{C}$ for 30 minutes before testing. For alternative complement pathway activation, $0.5 \mathrm{ml}$ zymosan was added to 0.5 $\mathrm{ml}$ of the same control serum and incubated at $37^{\circ} \mathrm{C}$ for 30 minutes before testing.

The study population comprised a total of 80 healthy blood donors who were used as the control group ( 40 women and 40 men, age range 20-64) and 144 patients who were divided into eight disease groups. Details are summarised in table 1 .

Patients with liver disease were referred from the Liver Unit at the Queen Elizabeth Hospital, Birmingham. They included six patients with primary biliary cirrhosis and four with chronic active hepatitis. There were single cases of $a_{1}$ antitrypsin deficiency, haemachromatosis, non-A non-B hepatitis, 3,4-methylenedioxymethamphetamine ("ecstasy") induced jaundice, fulminant hepatitis, possibly induced by a non-steroidal inflammatory drug, hepatoma, alcholic cirrhosis, together with a 6 year old boy who had been transplanted for cryptogenic cirrhosis. Renal patients were referred from the Renal Unit at the Queen Elizabeth Hospital, Birmingham. They included five patients with membranous glomerulonephritis, two with mesangioproliferative glomerulonephritis, three with focal

Table 1

\begin{tabular}{lccc}
\hline Groups tested & Males & Females & Age Range \\
\hline Controls & 40 & 40 & $20-64$ \\
Liver disease & 10 & 10 & $6-76$ \\
Renal disease & 14 & 6 & $22-72$ \\
SLE (normal C3 and C4) & 3 & 17 & $19-66$ \\
SLE (low C3 and C4) & 1 & 19 & $6-56$ \\
Rheumatoid arthritis & 2 & 18 & $12-27$ \\
Primary hypogamma- & 16 & 4 & $11-72$ \\
globulinaemia & 2 & 2 & $17-48$ \\
C7 deficiency & & & \\
\hline
\end{tabular}

segmental glomerulosclerosis, four with minimal change disease and four with IgA nephropathy. The patients with SLE were referred from rheumatologists and nephrologists in the West Midlands. All patients with SLE had antibodies to double stranded DNA: they were divided into two groups, those with normal $\mathrm{C} 3$ and $\mathrm{C} 4$ concentrations and those with low $\mathrm{C} 3$ and $\mathrm{C} 4$ concentrations. Patients with seropositive rheumatoid arthritis were referred from the rheumatologists at East Birmingham Hospital and the patients with primary hypogammaglobulinaemia attended the Regional Immunology Department, East Birmingham Hospital. Four members from a family with $\mathrm{C} 7$ deficiency were also studied. One was homozygous C7 deficient and the others were heterozygous for the deficiency. All were clinically well at the time blood was taken.

Serum samples obtained from control subjects and patients were separated, aliquoted, and stored at $-20^{\circ} \mathrm{C}$ before testing. Vitronectin concentrations were measured using a single radial immunodiffusion assay (The Binding Site, Birmingham, England). A calibrator was provided with the kit and serum samples were tested neat. The radial immunodiffusion plates were read after 48 hours. C3 and C4 concentrations were measured by nephelometry (Behring): SPS-01 (Supra Regional Specific Protein Unit, Sheffield) was used as the serum calibrant.

Statistical analysis was performed using the Mann-Whitney $U$ test and the Spearman rank correlation coefficient test.

\section{Results}

The first control sample gave a percentage recovery of $100 \%$ at 1 in 2,1 in 4 , and 1 in 8 dilutions. The second control sample gave a percentage recovery of $82 \%$ at the 1 in 2 dilution and $100 \%$ at the 1 in 4 and 1 in 8 dilutions. It was impossible to read the ring diameter of the 1 in 16 dilution. The control serum samples behaved in a similar manner to the calibrator.

Intrabatch analysis $\mathrm{CV}$ for the control sample, when tested neat, was $1.99 \%$ and $3.32 \%$ at the 1 in 2 dilution. The interbatch analysis $\mathrm{CV}$ for the control serum sample was $4 \cdot 5 \%$.

There was no significant difference obtained between measuring vitronectin concentrations in serum and plasma (EDTA) samples.

There was no significant difference between serum vitronectin concentrations of samples stored at $-20^{\circ} \mathrm{C}$ and $-70^{\circ} \mathrm{C}$. Vitronectin concentrations in both serum samples stored at $37^{\circ} \mathrm{C}, 4^{\circ} \mathrm{C}$, and room temperature were reduced (18-24\%) when compared with samples stored at $-20^{\circ} \mathrm{C}$.

Serum vitronectin concentrations measured in control samples heated to $56^{\circ} \mathrm{C}$ were reduced $(23-27 \%)$ when compared with samples stored at $-20^{\circ} \mathrm{C}$.

The serum vitronectin concentration was decreased by $51 \%$ following activation of the 
Table 2

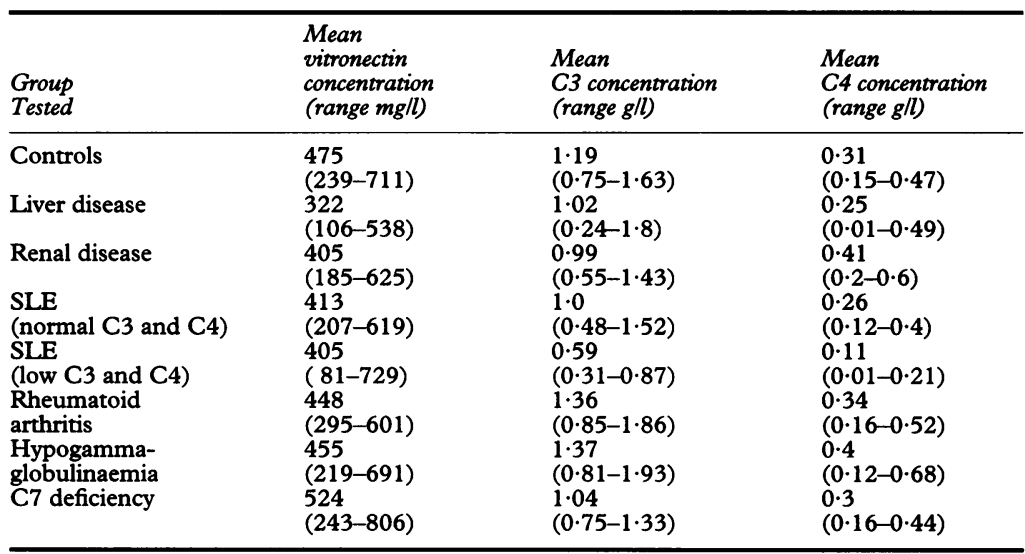

alternative complement pathway. Activation of the classical complement pathway did not result in a decrease in vitronectin.

The mean concentration of vitronectin in serum from control subjects was $475 \mathrm{mg} / 1$ with quite a wide range (239-711). The distribution of concentrations in the controls

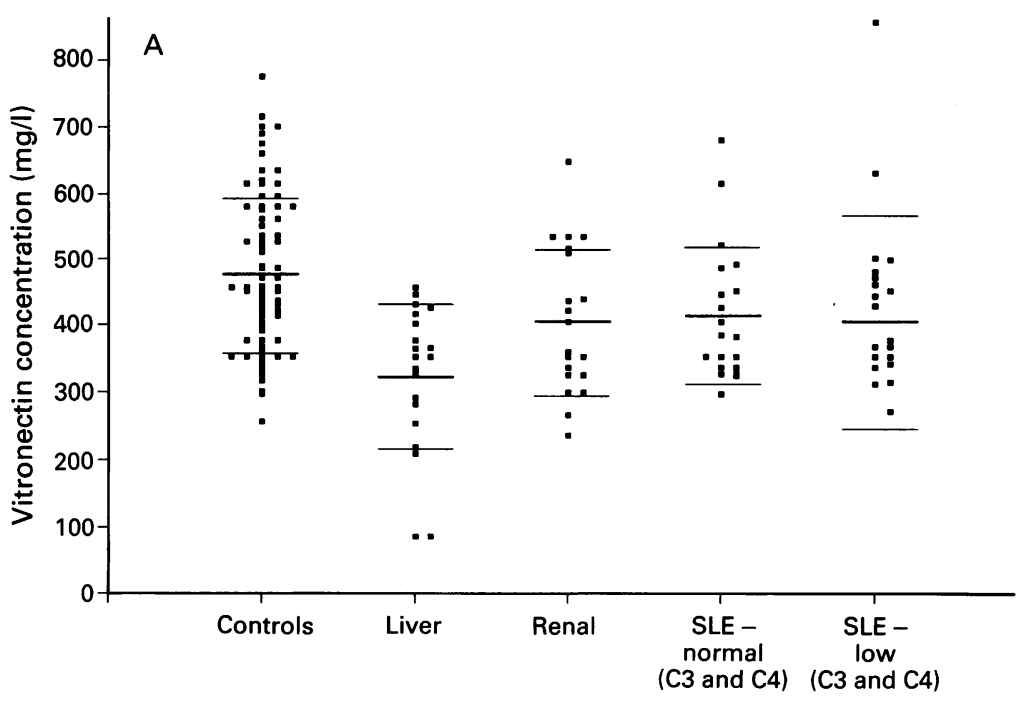

Figure $1 A$ Serum vitronectin concentrations in control subjects and patients with liver disease, renal disease, SLE with normal C3 and C4 concentrations and SLE with low C3 and $C 4$ concentrations. The horizontal lines indicate mean ISD.

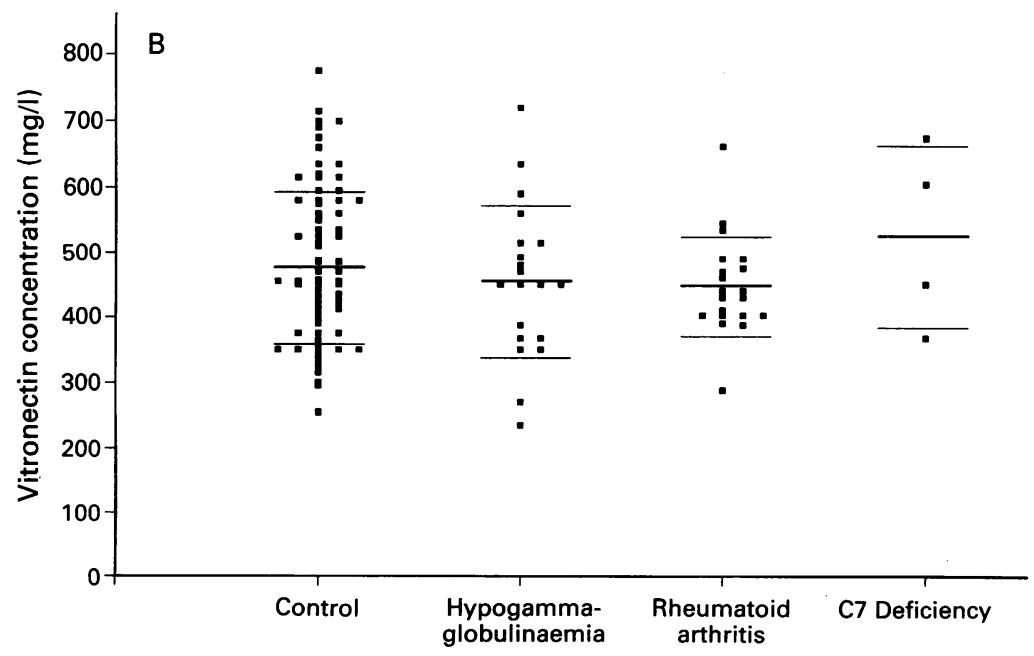

Figure $1 B$ Serum vitronectin concentration in control subjects and patients with primary hypogammaglobulinaemia, rheumatoid arthritis, and C7 deficiency. Horizontal lines indicate mean ISD. was not strictly linear, and as with a number of other plasma proteins, tended to be geometric. There was no significant difference between adult concentrations of serum vitronectin in men and women, and there was no significant change in concentrations with age. The mean concentrations and ranges of vitronectin, $\mathrm{C} 3$, and $\mathrm{C} 4$ calculated in the control subjects and patient groups are given in table 2.

The concentration of vitronectin in serum from patients with liver disease $(p<0.001)$, renal disease $(p=0.018)$, and SLE with normal C3 and C4 concentrations $(p<0.022)$ was significantly lower than in control subjects (fig 1A).

There was no significant difference in the concentration of vitronectin in serum from patients with SLE with low C3 and C4 concentrations, primary hypogammaglobulinaemia, rheumatoid arthritis, and $\mathrm{C7}$ deficiency when compared with control subjects (fig $1 \mathrm{~A}$ and $\mathrm{B}$ ). There was a significant correlation between the serum vitronectin concentration in patients with liver disease and $\mathrm{C} 4$ concentrations, $\mathrm{RS}=0.57 \quad(\mathrm{p}=$ 0.008 ).

\section{Discussion}

Vitronectin concentrations in plasma have already been measured by rocket immunoelectrophoresis ${ }^{19}$ and ELISA techniques. ${ }^{25} \mathrm{We}$ evaluated a radial immunodiffusion method for the measurement of vitronectin. Our findings indicate that this commercially available kit (The Binding Site, Birmingham, England) is suitable for measuring vitronectin concentrations in serum samples stored at $-20^{\circ} \mathrm{C}$. While the precision of the method was satisfactory, it was not directly compared with any other method, because these are not yet commercially available. Vitronectin was not stable at $37^{\circ} \mathrm{C}$, room temperature, or $4^{\circ} \mathrm{C}$, and was denatured by heating to $56^{\circ} \mathrm{C}$ for 30 minutes. Activation of the alternative complement pathway by zymosan resulted in a decreased vitronectin concentration, but activation by aggregated IgG did not result in any significant change.

Serum vitronectin concentrations were measured in control subjects and patients with various diseases. The mean concentration in control subjects was $475 \mathrm{mg} / \mathrm{l}$ (range 239-711). The present study confirmed previous reports that serum vitronectin concentrations in adult men and women do not differ and that there is no significant change with age. ${ }^{4}$ It also confirmed that there is no significant difference between vitronectin concentrations measured in serum and plasma (EDTA) samples. ${ }^{28}$

There was a significant reduction in the serum vitronectin concentration in our group of patients with liver disease, but there were insufficient cases of any one condition to permit correlation with the vitronectin concentration. In the group of patients with liver disease the $\mathrm{C} 4$ concentration correlated with the serum vitronectin concentration. 
Decreased plasma vitronectin concentrations have been found before in patients with chronic liver disease, and significantly reduced concentrations in patients with liver cirrhosis. In the present study significantly reduced serum concentrations of vitronectin were also found in patients with renal disease and patients with SLE with normal C3 and $\mathrm{C} 4$ concentrations. The numbers of patients in these groups, however, were again small. There was no significant difference in the serum vitronectin concentration in the groups of patients with SLE with reduced C3 and $\mathrm{C} 4$ concentrations, rheumatoid arthritis, or primary hypogammaglobulinaemia. Decreased C3 and C4 concentrations in some patients with SLE suggest active disease with activation of the classical complement pathway. It is interesting that in vitro activation of the classical complement pathway did not produce a reduction in the vitronectin concentration either. While it is difficult to explain why patients with SLE with normal C3 and C4 concentrations had significantly low vitronectin concentrations, this may be because of alternative pathway activation in these patients or some non-immune complex mediated mechanism.

Inherited deficiencies of most regulatory complement proteins have been found in humans and disease associations are well recognised. But no genetic deficiency of vitronectin has been reported hitherto.

While a reduction in vitronectin concentrations were found in the groups mentioned above, the changes were less striking than those in other routinely measured parameters, and it seems that this test is only a modest addition to the methods for the laboratory assessment of such patients in clinical practice. To understand the importance of reduced serum concentrations of vitronectin in disease, however, and its possible implication in pathogenic processes, a larger study is required.

1 Holmes R. Preparation from human serum of an alphaone protein which induces the immediate growth of unadapted cells in vitro. $₹$ Cell Biol 1967;32:297-308.

2 Jenne D, Stanley KK. Molecular cloning of S-protein, a link between complement, coagulation and cella link between complement, coagulation

3 Steen K. Epibolin: a protein of human plasma that supports epithelial cell movement. Proc Natl Acad Sci USA 1981;78:6907-11.

4 Shaffer MC, Foley TP, Barnes W. Quantitation of spreading factor in human biological fluids. $\mathfrak{F} \mathrm{Lab} \mathrm{Clin} \mathrm{Med}$ 1984;103:783-91.

5 Hayman EG, Pierschbacher MD, Ohgren Y, Ruoslahti E. Serum spreading factor (vitronectin) is present at the cell surface and in tissues. Proc Natl Acad Sci USA 1983;80:4003-7.

6 Podack ER, Muller-Eberhard J. Isolation of human S- protein, an inhibitor of the membrane attack complex of complement. f Biol Chem 1979;254:9908-14.

7 Podack ER, Dahlback B, Griffin JH. Interaction of Sprotein of complement with thrombin and antithrombin III during coagulation. $¥$ Biol Chem 1986;261:7387-92.

8 Preissner KT, Wassmuth R, Muler-Berghaus G. Physiochemical characterization of human S-protein and its function in the blood coagulation system. Biochem f 1985;231:349-55.

9 Bhakdi S, Kaflein R, Hastensen TS, Hugo F, Preissner KT, Mollnes TE. Complement S-protein (vitronectin) is associated with cytolytic membrane-bound C5b-9 complexes. Clin Exp Immunol 1988;74:459-64.

10 Bhakdi S, Hugo F, Tranum-Jensen J. Functions and relevance of the terminal complement sequence. Blut 1990 60:309-18.

11 Dahlback B, Podack ER. Characterization of human Sprotein, an inhibitor of the membrane attack complex of complement. Demonstration of a free reactive thiol group. Biochemistry 1985;24:2368-74.

12 Preissner KT, Muller-Berghaus G. S-protein modulates the heparin-catalyzed inhibition of thrombin by the heparin-catalyzed inhibition of thrombin

13 Barnes DW, Vander Bosch J, Mujazaki K, Sato G. The culture of human tumour cells. Methods Enzymol 1981;79:368-91.

14 Anonymous [editorial]. Fibronectins and vitronectin. Lancet 1989;i:474-6.

15 Pytela R, Piershbacher M, Ruoslahti E. A 125/115 KDa cell surface receptor specific for vitronectin interacts with the arginine-glycine-aspartic acid adhesion sequence derived from fibronectin. Proc Natl Acad Sci USA 1985;82:5766-70.

16 Ruoslahti E. Fibronectin and its receptors. Ann Rev Biochem 1988;57:375-413.

17 Fryklund L, Sievertsson H. Primary structure of somatomedin B. FEBS Letts 1978;87:55-60.

18 Heldin C, Wasteson A, Fryklund L, Westermark B. Somatomedin B: mitogenic activity derived from contaminant epidermal growth factor. Science 1981;213: 1122-3.

19 Kemkes-Matthes B, Preissner KT, Langenscheidt F, Matthes KJ, Muller-Berghaus G. S-protein/vitronectin in chronic liver diseases: correlations with serum cholinesterase, coagulation factor $\mathrm{X}$ and complement components C3. Eur f Haematol 1987;39:161-5.

20 Preissner KT, Holzhuter S, Muller-Berghaus G Identification and partial characterization of platelet $S$ protein. Haemostasis 1988;18:149.

21 Hetland G, Pettersen HB, Mollness TE, Johnson E. Sprotein is synthesized by human monocytes and protein is synthesized by human monocytes and

22 Kanz L, Lohr GW, Preissner KT. Identification of human megakaryocyte vitronectin/S-protein. Blood 1988;72 (Suppl):372a.

23 Hayman EG, Engvall E, A'Hearn E, Barnes D, Pierschbacher M, Ruoslahti E. Cell attachment of replicas of SDS polyacrylamide gels reveals two adhesive plasma proteins. $\mathcal{F}$ Cell Biol 1989;95:20-3.

24 Akama T, Yamada KM, Seno N, et al. Immunological characterization of human vitronectin and its binding to glycosaminoglycans. $\mathcal{F}$ Biochem 1986;100:1343-51.

25 Conlan MG, Tomasini BR, Schultz RL, Mosher DF. Plasma vitronectin polymorphism in normal subjects and patients with disseminated intravascular coagulaand patients with dissemin

26 Sun WH, Mosher DF. Polymorphism of vitronectin Blood 1989;73:353-4.

27 Kubota K, Katayama S, Matsuda M, Hayashi M. Three types of vitronectin in human blood. Blood 1989;73 353-4.

28 Preissner KT, Jenne D. Structure of vitronectin and its biological role in haemostasis. Thromb Haemostas 1991;66:123-32.

29 Jenne D, Hugo F, Bhakdi S. Monoclonal antibodies to human plasma Protein $\mathrm{X}$ alias complement $S$ protein. human plasma Protein X

30 Brown C, Steen KS, Falk RJ, Woodley DT, O'Keefe, EJ. Vitronectin: effects on keratinocyte motility and inhibition of collagen induced motility. $\mathcal{F}$ Invest Dermato 1991;96:724-8.

31 Dahlback K, Lofberg $H$, Alumets J, Dahlback B. Immunohistochemical demonstration of age related depositions of vitronectin (S-protein of complement) and terminal complement complex on dermal elastic fibres. F Invest Dermatol 1989;92:727-33.

32 Inuzuka S, Ueno $\mathrm{T}$, Torimura $\mathrm{T}$, et al. Vitronectin in liver disorders: biochemical and immunohistochemical studies. Hepatology 1992;15:629-36. 